Journal of Education and Vocational Research

Vol. 2, No. 1, pp. 24-33, July 2011 (ISSN 2221-2590)

\title{
An Insight into Risk Identification, Quality and Productivity Enhancement using Six Sigma
}

\author{
Muhammad Usman Tariq*, M. Naeem Ahmed Khan \\ Shaheed Zulfikar Ali Bhutto Institute of Science and Technology (SZABIST), \\ Islamabad, Pakistan. \\ *usman_kazi2006@yahoo.com
}

\begin{abstract}
Six Sigma, with a myriad of its applications in numerous organizational and business processes, offers a project management methodology that supports achieving a goal of near perfection in process performance. Six Sigma is based on the impetus of Plan-Do-Check-Act can help industries, businesses and organizations to achieve significant performance improvement as most of the Fortune 500 companies have adopted Six Sigma (DeFeo \& William, 2004). Six Sigma initiatives primarily entail DMAIC and DMADV methods for attaining a high standard of quality. In this paper we provide a critical analysis of the various Six Sigma applications, techniques and tools that can be used for improving quality and productivity of the organizations. The study also provides an insight into the methods used for risk identification in Six Sigma. The proposed techniques are evaluated and analyzed viz-a-viz DMAIC and DMADV approaches. The objective of this research is to summarize the existing level of research in the field of Six Sigma and highlighting the need for intensive academic research in this area. The study comparatively analyzes Six Sigma with Lean, QFD, PSP/TSP, FMEA, TPRM, AHP/ISS and PMBOK requirements. The study also highlights the prospective areas of future/further research in this discipline. The critical analysis of various techniques studied as part of this research reveals that Six Sigma is primarily beneficial for process improvement, risk identification and management etc. The critical analysis of this study is reported herein.
\end{abstract}

Keywords: Six Sigma, FMEA, PSP/TSP, TPRM, Risk identification and Management

\section{Introduction}

Bill Smith at Motorola initially introduced Six Sigma as a set of practices for improving manufacturing processes and reducing defects. Later on, Six Sigma methodology was extended for improving numerous organizational and business processes and a number of companies imaginatively used it to maximize profit by improving their business processes. Six Sigma is a widely used methodology in different domains for process improvement and Six Sigma is also applied for software process improvements. Six Sigma is often termed as problem solving methodology - a statistical method for improving organizational and business processes (DeFeo \& William, 2004). Being a project methodology, Six Sigma is a customer focused approach for performance gain and many businesses have adopted as a strategy to achieve world class performance.

Sigma $(\sigma)$ is a statistical unit of measure that reflects process capability. Sigma scale of measure may be correlated to defects-per-unit, parts-per million defects or probability of error. There are a number of ways to define Six Sigma. From business perspective, it is considered as a break-through strategy to significantly enhance customer satisfaction and business value by reducing variability in all aspects of business. However, technically, it is a statistical term signifying 3.4 defects per million opportunities (DeFeo \& William, 2004). Six Sigma consists of two approaches; define-measure-analyze-improve-control (DMAIC) and define-measureanalyze-design-verify (DMADV) or DFSS. DMAIC consists of five phases: Define, Measure, Analyze, Improve and Control. It is used for improving the existing business processes. These five phases play a pivotal role in improving the processes. The Define phase is used for defining the problem using voice of customer and project goals. The Measure phase is used for measuring the current processes and collecting related data. The Analyze phase is used for finding the root cause of the problems and considering all the factors. The Improve phase is used for optimization of the current processes based on different data analyzing techniques. The Control phase is used for controlling the state of the process and ensuring that any problem that can occur is corrected before it results in error or defect. 
DMADV also consists of five phases, but with a relatively different connotation and concept as compared to DMAIC phases. DMADV is used for creating new processes or new product. Here, the Define relates to goals setting for making design according to the customer requirements. The Measure phase identifies and assesses critical factors to quality capability of product and associated risks. The Analyze phase relates to design alternative and high level designs and choosing the proper design to be implemented. In the Design phase, activities involving improvement of design and planning for verification of the design are carried out and simulations may be involved at this stage. Finally, in the Verify phase, the design is verified and the processes are implement and are handed over to process owners. DMADV is also knows as DFSS (Design for Six Sigma).

Lean Six Sigma is another approach which is used on the same lines as Six Sigma. The main difference is that lean software methodology is geared towards eliminating those processes which do not increase productivity and such processes are named as waste. The main model used in practicing lean is to identifying the value, defining the value stream, flow determination, defining pull and improving the process. Lean focuses on flow of process. Mostly tools are visualization tools such as Microsoft Visio to mention the flow of the overall processes. On the other hand, Six Sigma is based on DMAIC method and it focuses on problem and finding root cause of the problem using statistical methods. Another difference between lean processes and Six Sigma is that lean does not include statistics whereas the tools used in both the methodologies are the same. Lean focuses on eliminating the waste and non value services. Lean focuses on training $100 \%$ of the organization whereas Six Sigma focuses on training only $25 \%$ of the organization and focusing the other parts like finding the root cause of the problem.

Motivation for Research: Six Sigma is a quality standard used in industries and corporate sectors. Being motivated with the specialized tools and techniques offered by Six Sigma, we endeavor to carry out a critical of analysis of different techniques to highlight how they can be employed and exploited by the organizations and business to enhance their productivity, quality of products and improving the overall processes; thus, ultimately succeeding throughout the development stages of projects. Since Six Sigma lacks risk handling processes apart from Root Cause Analysis (RCA), the study also offers an insight into different risk management frameworks that can be effectively utilized to improve the productivity. Since risk identification and handling is always a major concern of the industry in real time environment, therefore, it is also an allied motivation for undertaking the study. The paper is organized into five sections. An introduction of Six Sigma and its approaches is described in this section. Section II provides an overview of the existing Six Sigma tools and techniques. A critical analysis of various Six Sigma based tools and techniques proposed by different researchers is provided in section III which is primarily based on the evaluation of the literature review. Section IV suggests some future dimensions to this research. Finally, we conclude in the last section.

\section{Literature Review}

Santos and Cabral (2008) draw comparison among the important concepts related to risk management tools and techniques. TWO important concepts are FMEA (Failure Mode and Effect Analysis) and PMBOK (Project Management Body of Knowledge). FMEA is used for identifying possible failure risk in a specific project processes as well as the whole product. FMEA is combined with PMBOK to utilize both the techniques to create a new model for identification of risk. In Information Technology projects, cost overrun is very common and to make a project successful, proper implementation of risk management is required. The gap analysis conducted between the suggested model and PMBOK risk management model insinuates to use risk management of PMBOK. The comparison of results show that FMEA can be used as a beneficial tool with PMBOK risk management as it has been implemented successfully in the real time environment. Their model also identifies a number of unforeseen risks that usually result in the failure of IT projects. Severity and detection has been the main focus of the whole comparison and model. The model had been successfully implemented in the mailing system of Brazil.

Zhang, Hill and Gilbreath (2009) highlight the needs and importance of conducting wide-ranging research on Six Sigma. Since Six Sigma minimizes the product defects to a very low level, therefore, many industries are implanting it to improve their productivity. The main issue that needs to be acknowledged is that Six Sigma is an industrial implementation and hardly any industry shares the knowledge due to its policies and cost incurred on implementing Six Sigma. The available literature is also not sufficient to conduct an extensive 
research; however, the authors have provided a critical analysis of Six Sigma approach and highlighted new directions to conduct research in this area. The Six Sigma is defined in terms of defect rate metric, tool, improvement program and an improvement philosophy. Moreover, Six Sigma research issues are also identified that provide in-depth details of the problems. Theoretical foundation of Six Sigma suggests that it is useful for process improvement, organization science, approach for dynamic environment, human resources management and innovation. The reported study provides interesting context for different fields that need further research to be conducted to improve the overall business processes

Wang (2008) discusses four issues that relate to subcategory of Six Sigma. These issues relate to basic concept of Six Sigma, DMIAC (an acronym that stands for Define, Measure, Analyze, Improve and Control) process, DFSS (an acronym that stands for Design for Six Sigma) and deployment. One of the foundations of Six Sigma is based on standard deviation of the process which should be six times greater than the mean of process. The DMIAC process is followed for defining the projects. The define phase has always been an important segment as selection of the project is one of the major issues in the industry. Most of the researchers and practitioners criticize on the process but do not suggest course of action to improve or enhance the process. Same is the case with DFSS process that is based on utilizing the tools, trainings and measurements that are needed to design the product and process that are required to improve the process. The business aspects of Six Sigma define the practical implementation of Six Sigma in different fields. Success factors are also discussed that ensure the implementation of Six Sigma.

Hsieh, Manduca and Lin (2007) combine IT with statistics of Six Sigma as the later is based on strategic management linking with the statistical approach and the whole system is based on DMIAC process. The theme of the Six Sigma is to focus on customer wants, factual decisions based on data, process, management, improvement, organizing the data, mulling over on all the stakeholder that are linked with the project and a space for experimentation. All these characteristics when combined together give perfection for Six Sigma. These approaches have different goals to be achieved for improvement of the processes. Six Sigma involves many tools such as control charts, fishbone and failure mode analysis that help to analyze the data and find out the actual cause of the defect. IT has combined together all of these concepts in a detailed study known as Quality Function Deployment (QFD) and is also known as House of Quality. The methodology of QFD is a set of weighted relationships between the requirements and level characteristics. It embeds the customer requirements into design parameter for products, processes and control of the whole process. Azizi and Hashim (2008) present a basic level framework for risk assessment at industrial level by defining an approach for managing risk in project management and other models that can assist in understanding the functions of risk management. The author state that all the calculations involved in businesses are based on tools, software, network and root cause of generation of risk primarily depends on the machines as these are not error free. In addition, very less research is carried out in the area of enterprise level risk management. Earlier, some frameworks were developed such as ARMF (Alternative Risk Management Framework) but it covers only three components theoretical risk management, applied risk management and model implementation. Some of the major frameworks that cover IT activities in organizations are ITIL (IT Infrastructure Library), COBIT (Control Objective for Information and related Technology), P3M3 (Portfolio, Programme and Project Management Maturity Model) and ISMS (Information Security Management System). ISMS relates to the latest security issues in IT infrastructure. In relation to the aforementioned frameworks, the authors propose a framework that links all these together but it is merely based on only two attributes: questions and history. The authors have also carried out a low level analysis of components of other frameworks that are involved in enterprise level risk management.

According to Rovai et al. (2006), project success is based on evaluating and managing the risks that occur during the execution of projects and the basic model presented by PMBOK is widely used in project risk management. Their model also uses the same strategy of identifying, evaluating, monitoring and controlling the risk as outlined by PMBOK. Their model is divided into four phases: analysis, synthesis, implementation and performance. The analysis phase is a diagnostic phase which diagnoses the organizational processes. The synthesis phase defines the requirements to handle the identified risk. The implantation phase structures the changes that are needed in the organization. Finally, the performance phase is concerned with evaluation of risks that occur in the project. Their model also evaluates the team performance with predefined evaluation parameters and decisions are based on the results derived from the evaluation. These parameters are further 
combined with three tactical layers: - process competencies, managerial and culture. Their proposed model is implemented in a multinational organization based in Italy to validate its performance. The results of their study show that project risk level in larger organizations is still at initial stage. The lesson learned is always the most important part of any research and authors state that further research is needed to evolve the model to reach high levels of growth and efficiency. The model is validated through implementation, but the biggest shortcoming detected in their research is that a project is mostly dependent on managers and stakeholders and most of the time project fails due to inability of project manager to mitigate the risks.

Seyedhoseini and Hafeti (2009) compare RMP (risk management process) with many mostly used RMP's such as RISKIT (Risk related to information technology) for software engineering, and PMBOK for project management and AS/NZS 4360 (risk management standard) for public applications. The approach gives importance to all steps of RMP as the key concept involved in project environment are project measure, project scope, project ultimacy (ultimate stage of project),risk event, risk measure, risk class and response action. The TPRM framework is targeted towards use for customized project environment. The elements are derived in context with the risk and response and consist of different stages, phases and steps. The first phase involved in TPRM is start up in which a leader of risk management is appointed by the project manager. The next phase is actuation which is used to establish the TPRM plan. The next phase is assessment of project risk and responses and is further divided into identification and analysis. Afterwards, risk and response identification is done followed by risk response analysis. Risk and response measurement phase analyze the impact of the risk and its corresponding responses on the project. The processing phase processes the responses and prioritizes them accordingly. To analyze the risk and responses in an effective manner, a spectrum is generated in which total risk and response level combine together the estimates in a single measurement. TPRM shutdown is the last stage that guarantees that the process has been completed. The model is practically implemented in a construction environment to analyze its effectiveness. A comparison is also conducted between the latest model of PMBOK risk management and TPRM and it shows that there is no response typology in PMBOK.

Benedikt and Frank (2009) conduct research on IT outsourcing and a large part of the research relates to the risks involved in outsourcing of IT projects. Outsourcing means diverting the business to third party or other person that is external to the organization. IT outsourcing has been on its peek until 2008 and research has been conducted on managing the risks related to IT outsourcing, but most of the research was in fact targeted towards different domains and therefore created different methodologies. Project managers consider it an overhead and most of the time it was transferred to third party to reduce the cost. Most of the research was content oriented and no beneficial contribution was added to the knowledge. The review outlined in the paper provides summary of all the related work, analyzing research methods and experimental analysis of outsourcing. The authors highlight that all the research conducted in the past was based on general aspects of IT and the case studies and developed models were either incomplete or invalid. The author stress he need for construction of a reference model that is capable of implementing the approaches for IT outsourcing. The theories applied in IT outsourcing research were merely based on cost of deliverables or organizational theories. The main phases involved in IT risk management are identification, analysis, evaluation, monitoring, reviewing, communicating and continuous improvement. The risk factors involved in IT outsourcing should also be identified that range from wrong expected cost to bad performance. Further, lack of proper resource allocation causes failure of IT outsourcing process.

The methodology proposed by Racz, Weippl, and Seufert (2010) consists of three stages; orientation and scoping, model selection and analysis, and construction of integrated process model. Initially, three models are analyzed separately and then are merged together. The first selected process is orientation and scoping where definition of GRC is built that combines together the rules, components and objectives of GRC. The objective is to combine together high level IT processes so that the model can support management process execute the business and support processes in efficient manner in relevance to the three IT GRC processes. Once the scope is define, variety of standards and frameworks are analyzed before selection of base for each of the domain. For IT risk management, a general framework is selected on the basis of high level processes involved in risk management. IT compliance processes are selected on the basis of model derived in (Rath and Sponholz, 2009). The common attributes in the process models follow the same mechanism involved in 
PDCA (Plan, do, check and act) cycle and Six Sigma. Finally, all the three stages are merged together in the IT GRC management model.

Risk has always been an issue in projects execution and many projects fail due to uncertain and unexpected risks that surface during the execution. Soderholm (2008) provides a mechanism to deal with unexpected events that occur due to project environment. The prime issue is that most of the models are theoretical and do not contribute enough to what actually should be done in the practical environment. The existing models provide detail on what action to be taken to keep the project on track but lack guidance to deal with the unexpected events. Most of the research is based on case studies focusing on certain types of product and organization but real industrial production usually poses different scenarios. Financial and functional requirements sometime are more important which disturbs the cost and time schedules. Three major categories of events that effect the project execution include reopening, revisions and fine tuning. The first category deals with the stakeholders' relations, second deals with planning the projects and revising them periodically while the third category deals with motivation of team and relation among the team members.

Software project development and execution is particularly difficult as most of the new products require proper research before development but still carry a high risk factor. Though, a number of risks can be identified beforehand but still the probability of failure is greater. The main issue is that same technique cannot be applied to every domain as risk types for every domain differ. Above all, proper research lacks that can combine together the risk management in operating environment with the organizational tactics. Wang et al. (2010) focus on applying BSC (Balance score card) to measure the performance of R\&D organization in congruence with the vision and tactics of an organization. The BSC manager analyzes the organization with respect to customers, internal processes, growth, learning ability and cost related performance; and then develops the necessary metrics. There are five principles to implement BSC which are mostly derived from other research. QFD is used here to convert the performance measures of organization derived from BSC into performance measures of project which ensures achievement of the defined goals of organization as it is solely based on voice of the customers. Applying QFD increases efficiency, reduces cost and time. Their research combines together the BSC with QFD in a top down approach for risk management and the authors have implemented their model in a drug industry for validation.

Staveren (2007) extends the basic concepts of risk analysis combining with risk management using experiences and guidelines. Risk can be defined as unexpected occurrence of any event which has positive or negative effect on the development and execution of the project. Uncertain events are embedded within the risk that occurs unexpectedly. Risk analysis deals with analyzing the possible risk and their effects after occurrence and is aim toward minimizing the risk effects. One of the applied methods is Fault Tree Analysis (FTA) that deals with identifying all the possible risks. Another is Failure Mode and Effect analysis (FMEA) which is opposite to FTA and it deals with exploring a certain event, failure and risk with respect to the possible effects. Another advanced technique used is Failure Mode Effect and Criticality Analysis (FMECA) that deals with probability of failure and impact of effects. Risk must be managed for a successful project or process. GeoQ deals with the same concept and combines together risk analysis and risk management. The main purpose of GeoQ is to manage all the phases of projects during the life cycle of the project. Originally, GeoQ is made for construction projects and deals with timely and proper definition of the site selection. GeoQ risk management approach is divided in six general phases for projects and the phases include: feasibility, pre-design, design, contracting, construction, operation and maintenance. The number of phases can be minimized or increased according to the size of the project. The GeoQ further provides six risk management steps that are not flexible and must be applied in hierarchal way. The geotechnical risk management is strongly required in the current industry as size and complexity is growing day by day.

All the software projects are language and system dependent. The common factor involved in the development of a software project and help in creation of risk factors is demand uncertainty which caters for the knowledge of customers about the project. Another factor is frequent changes in demand of customers that leads to crucial interruptions in the development of the software and increases the risk factor to very high level. During the execution of project, some of the demands also seem to be out of scope and scope creep increases development time and cost of project as well. The frequent changes and complexity of the project also compromise its quality. Therefore, a proper risk management is required for software development 
projects. The demand analysis should start from the initial stage of the software development. In view of this, customer requirements should be categorized qualitatively in order to analyze the risks. Risk identification, analysis and response measures are the commonly used phases in risk management. AHP (Analytic Hierarchy Process) law classifies the risk into three categories: low, high and normal. Improved structure development method is divided into analysis, system design and system implementation. According to Deng and Ma (2008), the model is implemented on a case study in three steps by establishing the delivery model, constructing the judgment matrix and sorting in level and testing consistency. The results identify the risks and classify them according to the model.

Risk can be divided into different steps on the basis of their probability of occurrence in project execution as the sources of risks can be different. The reason for using risk management is different for different domains and depends on the environment in which a project is being executed. The existing literature shows that there had been many models with many different approaches for different domains. The proposed framework of Alhawari et al. (2008) introduces new phases that are essential for risk management life cycle. The main process starts from identifying the need for risk management for the organization and its importance to the organization. It also defines risk management importance for stakeholders and motivates them to join together for identifying risk associated with the commercial processes. All the risk must be identified to minimize the probability of occurrence. In the next step, the goal definition processes explains the organization and stakeholders' goals, limits and constraints. The next process is the most common process of identifying the risk that can cause cost and schedule overruns. The next phase is risk scrutiny in which every risk is analyzed. Risk analysis phase coverts the data into useful information and also works on probability of occurrence, measuring of probable loss and impact of risk. The data from analysis phase is filtered out in relevance to the objectives and goals of organization using risk verification process. The next phase takes the aforementioned information to plan, strategize and works on reducing the occurrence and impact of loss. Planning and experimentation phase tests the planning performed in the previous phase. Activities and safety control measures are performed according to the planning using risk implementation process. Risk control phase remains active during the whole life cycle of the project to control the risk and to ensure the applied approach is on the right path. Finally, the lessons learned are added to the education database to cope with the same risks in the subsequent projects.

Park, Choi and Baik (2007) suggest using Six Sigma tool in PSP/TSP to improve the overall process performance. The rate of failure of software projects is high and a lot of rework is involved if any defect is found. The quality of software products/services has been focused of researchers and many models and techniques are proposed. PSP/TSP are developed to fill the space of lacking knowledge and to provide commitment for success of software projects. Due to lack of proper statistical tools, the software processes cannot be measured and improved. For this purpose, Six Sigma is used in relation with the PSP/TSP but it is not an easy task to use Six Sigma as different data is required from different processes to PSP/TSP. The purpose of PSP is to provide an organized framework to carry out software development. It can be used with any coding language or design methods and covers almost all the required processes involved in software development. TSP, whereas, is developed to use PSP for development of commercial software and can be referred as customized PSP. The main difference is the creation of a very skilled team. TSP helps developers to produce quality products within the planned cost. Six Sigma on the other hand has toolset that vary with the organization and the employed approach. Therefore, after identifying the elements, a selection of proper Six Sigma tools is required for using with PSP/TSP. The process of combining the tools with PSP/TSP is started and activities of PSP/TSP are identified to provide input to Six Sigma tools. Some of the selected tools are cause and effect diagram, scatter plots, control charts, Pareto analysis and KANO analysis.

\section{Critical Evaluation}

Studies (Zhang, Hill \& Gilbreath, 2009; Wang, 2008) elaborate Six Sigma techniques and clear confusion in conducting research in Six Sigma. Zhang, Hill \& Gilbreath (2009) have highlighted different methods, techniques and research questions by defining Six Sigma in detail whereas Wang (2008) compares it with other approaches. However, research proposed in the later paper lacks general concept about Six Sigma statistics. 
Six Sigma has played an important role in IT sector (Hsieh, Manduca \& Lin, 2007; Benedikt \& Frank, 2009; Racz, Weippl \& Seufert, 2010). Hsieh, Manduca \& Lin (2007) discuss advantages of Six Sigma for IT based systems and suggest implementing FMEA approach to carry out parallel projects. Also, it uses concepts from the previous Six Sigma knowledge discussed by Zhang, Hill \& Gilbreath (2009). Benedikt \& Frank (2009) have conducted systematic research on IT sourcing by combining the concepts of IT based systems proposed in (Hsieh, Manduca \& Lin, 2007). It has combined huge amount of data together and no such research has been conducted in the past. Racz, Weippl \& Seufert (2010) introduce a new high level IT GRC model which is a substantial contribution to information system knowledge base. However, approach used in (Hsieh, Manduca \& Lin, 2007; Azizi \& Hashim, 2008) needs comprehensive validation before implementation in a real scenario. Moreover, a software tool is required to support the IT GRC model and further research is required for using proper Six Sigma tools for improvement of process, management and system (Hsieh, Manduca \& Lin, 2007; Park, Choi \& Baik, 2007). Park, Choi \& Baik (2007) provide overview of Six Sigma tools with PSP/TSP but it lacks the implementation tools and cannot be implemented at lower level due to knowledge and skill constraints.

Project management approaches are very effective in successful execution of projects (Santos \& Cabral, 2008; Soderholm, 2008; Deng \& Ma, 2008). Model proposed by Santos \& Cabral (2008) is quite simple and effectively identifies the risks and minimizes their harmful effects. The model also fulfils $71 \%$ of PMBOK requirements but lacks specific information (e.g., proper statistical data analysis technique to weight the severity) for project management. Soderholm (2008) only describes three events that could occur in project management practices. Whereas, Deng \& Ma (2008) focus on development of large scale projects based on user demands and advocates for assigning priority to the users. All of these approaches have limited scope and the research is quite narrow as the model proposed by Deng \& Ma (2008) is dependent on Matlab software that requires a specialized training for the user to implement and calculate values. The research conducted by Santos \& Cabral (2008) is limited to FMEA technique and does not cover comparison with other techniques, therefore, a detailed evaluation is needed to verify the robustness of the model.

Models proposed in (Azizi \& Hashim, 2008; Rovai, Rodrigues \& Campanario, 2006; Seyedhoseini \& Hatefi, 2009; Wang et al., 2010; Staveren, 2007; Alhawari et al., 2008) provide different techniques and encompass different aspects of risk management. Azizi \& Hashim (2008) mention five critical components involved at enterprise level risk management including infrastructure development, office level support, operations, software development and outsourcing management. The model proposed by Rovai, Rodrigues \& Campanario (2006) is very effective for organizations of the developing countries and is an important contribution. Their model is verified through implementation but is highly dependent on the data gathered in the risk management process which needs to be accurate as the critical factor of their model is reliability on the data. A meticulous and detailed framework for risk management is provided in (Staveren, 2007; ). Staveren (2007) has named this concept as GeoQ and Alhawari et al. (2008) have exhaustively defined the processes involved in risk management framework. The studies reported in (Seyedhoseini \& Hatefi, 2009; Wang et al., 2010) focus on dealing and providing new concepts for dealing with risks, however, these concepts are merely based on dealing with risk within the project execution and therefore are environment dependent. Seyedhoseini and Hatefi (2009) focus on response and risk whereas Wang et al. (2010) concentrated on two concepts QFD and BSC and linkage of organization tactics to avoid the effect of environment. The proposed framework of Seyedhoseini and Hatefi (2009) is deeply linked with other phases and the authors have also drawn comparison at different stages and processes to clear the vision of TPRM model. Their model is generic and does not provide details about the tools and techniques required to conduct the phases. The approaches proposed of (Azizi \& Hashim, 2008; Seyedhoseini \& Hatefi, 2009; Wang et al., 2010; Staveren, 2007) are dependent on different environmental effects and members of a team. A critical analysis of literature review is summarized in Table 1. 
Table 1: Critical Analysis of Six Sigma Techniques

\begin{tabular}{|c|c|c|c|}
\hline Author & $\begin{array}{l}\text { Method/ } \\
\text { Technique }\end{array}$ & Key Characteristics & Key points \\
\hline $\begin{array}{l}\text { Santos \& Cabral } \\
(2008)\end{array}$ & FMEA and PMBOK. & $\begin{array}{l}\text { Identification of } \\
\text { Risks and } \\
\text { Comparative } \\
\text { Analysis with other } \\
\text { approaches. }\end{array}$ & $\begin{array}{l}\text { Identifies the risks and minimizes } \\
\text { their harmful effects. It fulfils } 71 \% \text { of } \\
\text { PMBOK. }\end{array}$ \\
\hline $\begin{array}{l}\text { Zhang } \\
\text { et al. (2009) }\end{array}$ & $\begin{array}{l}\text { Methods, techniques and } \\
\text { research questions } \\
\text { supplemented with proper } \\
\text { definition of Six Sigma. }\end{array}$ & Statistical Analysis. & $\begin{array}{l}\text { Touches some core issues for } \\
\text { conducting research in Six Sigma }\end{array}$ \\
\hline Wang (2008) & $\begin{array}{l}\text { Basic level statistical } \\
\text { based approach }\end{array}$ & $\begin{array}{l}\text { Statistical Analysis } \\
\text { and Comparison with } \\
\text { other approaches. }\end{array}$ & $\begin{array}{l}\text { Defines and compares statistical } \\
\text { processes involved in Six Sigma with } \\
\text { different approaches. }\end{array}$ \\
\hline $\begin{array}{l}\text { Hsieh } \\
\text { et al. (2007) }\end{array}$ & $\begin{array}{l}\text { Using Six Sigma with IT } \\
\text { based systems. }\end{array}$ & $\begin{array}{l}\text { IT based approach } \\
\text { and emphasis on } \\
\text { Reliability of data. }\end{array}$ & $\begin{array}{l}\text { Implementation of FMEA approach. } \\
\text { Presentation of data using IT based } \\
\text { systems for implementation of Six } \\
\text { Sigma. However, no proper tools for } \\
\text { implementation are identified. }\end{array}$ \\
\hline $\begin{array}{l}\text { Azizi \& Hashim } \\
(2008)\end{array}$ & $\begin{array}{l}\text { Critical components } \\
\text { involved at enterprise } \\
\text { level in IT are identified. }\end{array}$ & $\begin{array}{l}\text { Identification of } \\
\text { Risks and Reliability } \\
\text { on data. } \\
\text { IT based approach. }\end{array}$ & $\begin{array}{l}\text { Combines together components from } \\
\text { different frameworks i.e., ITIL, P3M3, } \\
\text { COBIT, ISMS. }\end{array}$ \\
\hline $\begin{array}{l}\text { Rovai et al } \\
(2006)\end{array}$ & $\begin{array}{l}\text { Effective model for } \\
\text { organizations in } \\
\text { developing countries. } \\
\text { Strategic layers and } \\
\text { Project Management are } \\
\text { combined and } \\
\text { Performance evaluation } \\
\text { system is used. }\end{array}$ & $\begin{array}{l}\text { Identification of } \\
\text { Risks. } \\
\text { Risk Management. } \\
\text { Reliability on data. } \\
\text { Performance } \\
\text { evaluation. }\end{array}$ & $\begin{array}{l}\text { Six Sigma is used as tool and attempt } \\
\text { is made to embed it in the process. } \\
\text { The approach is highly dependent on } \\
\text { data. Further, performance evaluation } \\
\text { system is limited to team level. }\end{array}$ \\
\hline $\begin{array}{l}\text { Seyedhoseini \& } \\
\text { Hatefi (2009) }\end{array}$ & $\begin{array}{l}\text { Focuses response and risk. } \\
\text { A new model called TPRM } \\
\text { (Two pillar risk } \\
\text { management) is } \\
\text { introduced. }\end{array}$ & $\begin{array}{l}\text { Identification of } \\
\text { Risks and } \\
\text { Risk Management. }\end{array}$ & $\begin{array}{l}\text { Response strategy is well defined and } \\
\text { expanded framework is provided. The } \\
\text { model is implemented in one context } \\
\text { and needs to be implemented in other } \\
\text { fields to validate its effectiveness. }\end{array}$ \\
\hline $\begin{array}{l}\text { Benedikt \& Frank } \\
\text { (2009) }\end{array}$ & $\begin{array}{l}\text { IT outsourcing has been } \\
\text { focused. }\end{array}$ & $\begin{array}{l}\text { Extensive evaluation } \\
\text { and } \\
\text { IT based approach. }\end{array}$ & $\begin{array}{l}\text { Thorough research is conducted on IT } \\
\text { outsourcing. New ideas are presented } \\
\text { to conduct research in field of IT. }\end{array}$ \\
\hline Racz et al. (2010) & IT GRC model. & IT based approach. & $\begin{array}{l}\text { Model provides substantial } \\
\text { contribution to information system } \\
\text { knowledgebase. }\end{array}$ \\
\hline $\begin{array}{l}\text { Soderholm } \\
\text { (2008) }\end{array}$ & Project Management. & $\begin{array}{l}\text { Project Management. } \\
\text { Risk identification. }\end{array}$ & $\begin{array}{l}\text { Covers events that occur in project } \\
\text { environment. No proper review of } \\
\text { strategies to deal with unexpected } \\
\text { events is provided. }\end{array}$ \\
\hline
\end{tabular}


Table -1 Continued

\begin{tabular}{|c|c|c|c|}
\hline $\begin{array}{l}\text { Wang et al. } \\
(2010)\end{array}$ & $\begin{array}{l}\text { Focused on using QFD and } \\
\text { BSC linked with } \\
\text { organization tactics. }\end{array}$ & $\begin{array}{l}\text { Project Management. } \\
\text { Risk Management. }\end{array}$ & $\begin{array}{l}\text { Implements QFD and BSC to avoid the } \\
\text { environmental effect. Treats risks as } \\
\text { negative effects. Cannot deal with risk } \\
\text { in real time environment. }\end{array}$ \\
\hline Staveren (2007) & $\begin{array}{l}\text { Geotechnical risk } \\
\text { management. }\end{array}$ & Risk management & New framework GeoQ is introduced. \\
\hline $\begin{array}{l}\text { Deng \& Ma } \\
(2008)\end{array}$ & $\begin{array}{l}\text { Analytic Hierarchy Process } \\
\text { (AHP) is proposed that } \\
\text { improves structure } \\
\text { system. }\end{array}$ & $\begin{array}{l}\text { Risk management } \\
\text { Project Management }\end{array}$ & $\begin{array}{l}\text { Develop large scale projects based on } \\
\text { user demands. Techniques are applied } \\
\text { using software. }\end{array}$ \\
\hline $\begin{array}{l}\text { Alhawari et al. } \\
\text { (2008) }\end{array}$ & $\begin{array}{l}\text { Risk management } \\
\text { framework for project } \\
\text { execution }\end{array}$ & $\begin{array}{l}\text { Risk management. } \\
\text { Project Management }\end{array}$ & Better risk management processes. \\
\hline $\begin{array}{l}\text { Park } \\
\text { et al. (2007) }\end{array}$ & $\begin{array}{l}\text { PSP/TSP approaches for } \\
\text { Six Sigma are identified }\end{array}$ & $\begin{array}{l}\text { Statistical approach } \\
\text { which is compared } \\
\text { with other } \\
\text { approaches. }\end{array}$ & $\begin{array}{l}\text { Usage of Six Sigma tools with PSP/TSP } \\
\text { that is very beneficial for small teams } \\
\text { and individuals. }\end{array}$ \\
\hline
\end{tabular}

\section{Future Work}

The perspective future work to this research could be to look into formulating a robust model for minimizing the risks associated with various business and organizational processes. Particularly, a number of processes are prone to risk related to cost, schedule and quality of the products and services. The model will be supplemented with a framework that will deal with the uncertain risks and improvement of processes that are closely linked with the successful running of the project and will be validated through a case study. The future perspective also covers implementation of model in real time environment to check the robustness and handling of risks related to projects.

\section{Conclusion}

This study highlighted a critical overview of different technique that can considerably improve the quality and productivity of organizations. Besides, the study also looked into the probable methods that can be effectively adopted for risk identification within the Six Sigma framework. A data-driven process improvement undertaken using Six Sigma methodology amply caters for intrinsic risks associated with organizational and business processes. This study analyzed the key concept of Six Sigma with particular reference to quality, defect, process capability, variation and stability of operations. Though Six Sigma had been adopted by a number of organizations worldwide but the academic research in this area is still in its early stages. Generally, researchers think that Six Sigma is a management caprice due to which the pace of research activities in this area had been slower in the past. While quality management aspect of Six Sigma makes it customer-satisfaction oriented approach and the process improvement and risk management aspects make it a project management approach, nonetheless, the core theme of Six Sigma is based on variation reduction. This study analyzed the various uses and models of Six Sigma o highlight its effectiveness and the added benefits that organizations can get by improving their processes. Our study shows that the definition of Six Sigma varies amongst different organizations and businesses. The critical analysis made in this study show that Six Sigma presents a novel approach for quality management and risk management. The main contribution of this study is that it provides an insight into the current understanding of Six Sigma amongst many practitioners, current applications and practices of Six Sigma and the level of research activities being carried out in this field.

Recommendation: Finally, few recommendations are suggested that can be beneficial for the industries and the corporate sector. After a comprehensive analysis and review of various techniques, the study suggests that Six Sigma methodology improves the productivity and the industries and businesses should benefit from it for enhancing their efficiency and efficacy. The implementation of Six Sigma also improves the 
process that ensures that less cost is involved in the production of the specific product. All types of industries involved in any type of production may adopt this methodology for curtailing the defects in production and producing the quality products. Since risk management is essential part of the process, therefore, the methodology also helps identifying the uncertain risks in real time environment that can be embedded in Six Sigma tools that will help in producing quality products.

\section{References}

Alhawari S., Thabtah F., Karadsheh L,. \& Hadi, W. M. (2008). A risk management model for project execution. Paper presented at the 9th International Business Information Management Association Conference (IBIMA), Marrakech, Morocco.

Azizi, N., \& Hashim, K. (2008). Enterprise level it risk management. Paper presented at the 8th WSEAS International Conference on Applied Computer Science, Venice, Italy.

Benedikt, M., \& Frank, T. (2009). Why risk management matters in it outsourcing - a systematic literature review and elements of a research agenda. Paper presented at the 17th European Conference on Information Systems, Verona, Italy.

Deng, X., \& Ma, Z. (2008). Research on risk management of large-scale software project based on consumer's demand. Paper presented at the 38th International Conference on Computers and Industrial Engineering, Beijing, China.

De Feo, J. A., \& William W .B.. (2004).Juran Institute's Six Sigma Breakthrough and Beyond: Quality Performance Breakthrough Methods. New York, NY: McGraw-Hill Publishing Company Limited.

Hsieh, C. T., Manduca, B., \& Lin, B. (2007). Information technology and Six Sigma Implementation. Journal of Computer Information Systems Summer, 47(4), 1-10.

Park, Y., Choi, H., \& Baik, J. (2007). A framework for the use of Six Sigma tools in PSP/TSP. Paper presented at the 5th ACIS International Conference on Software Engineering Research, Management \& Applications, Busan, South Korea.

Racz, N., Weippl, E., \& Seufert, A. (2010). A process model for integrated IT governance, risk, and compliance management. Paper presented at the 9th International Baltic Conference on Databases and Information Systems, Riga, Latvia.

Rath, M., \& Sponholz, R. (2009). IT-Compliance: Erfolgreiches Management regulatorischer Anforderungen. London: Schmidt Erich Verlag.

Rovai, R. L., Rodrigues, L. C., \& Campanario, M. A. (2006). Strategic model for risk evaluation in project management. Paper presented at the 15th International Conference on Management of Technology, International Association for Management of Technology (IAMOT), Beijing, China.

Santos, D. \& Cabral, S. (2008). FMEA and PMBOK applied to project risk management. Journal of Information Systems and Technology Management, 5(2), 347-364.

Seyedhoseini, S.M. \& Hatefi, M.A. (2009). Two-pillar risk management (TPRM): a generic project risk management process. Transaction on Industrial Engineering, 16(2), 138-148.

Soderholm, A. (2008). Project management of unexpected events. International Journal of Project Management, 26, 80-86.

Staveren, M. T. (2007). Extending to geotechnical risk management. Paper presented at the 1st International Symposium on Geotechnical Safety and Risk, Shanghai, China.

Wang, H. (2008). A review of six sigma approach: methodology, implementation and future research. Paper presented at the 4th International Conference on Wireless Communications Networking and Mobile Computing (WiCOM), Dalian, China.

Wang, J., Lin, W., \& Huang, Y., (2010). A performance-oriented risk management framework for innovative R\&D projects. Technovation, 30(11-12), 601-611.

Zhang, W., Hill, A. V., \& Gilbreath, G. H. (2009). Six Sigma: a retrospective and prospective study. Paper presented at the POMS 20th Annual Conference, Orlando, Florida, U.S.A. 